\title{
PENGELOLAAN SUPERVISI MANAJERIAL PENGAWAS DI DABIN 7 UPTD PENDIDIKAN PURWODADI
}

\author{
Kustiyani $^{1)}$ dan Suyatmini ${ }^{2}$ \\ ${ }^{1)}$ UPTD Pendidikan Kecamatan Purwodadi \\ ${ }^{2}$ Magister Administrasi Pendidikan Sekolah Pascasarjana UMS \\ kustiyani64@gmail.com
}

\begin{abstract}
This study aimed to describe the managerial supervision planning, implementation of managerial supervision, and feedback managerial supervision supervisor in Dabin 7 UPTD District of Purwodadi. Qualitative research and ethnography used subjects school supervisors and principals. Data collection techniques usedh interviews, observation, and documentation. Data analysis techniques used the analysis of the flow of the process of collecting data through data reduction, data display and verification. The validity of the data used triangulation and source. The results of the study are 1) Planning managerial supervision includes, a. Preparation of supervision schedule managerial, b. Preparation of Instrument managerial supervision, c. Compile a list of schools to be supervised. 2) Implementation of supervision managerial. The three stages in the implementation of managerial are supervision, namely, initial activity, performance or core activities and the closing 3) The function of feedback is to improve the managerial supervision findings of non-compliance or overcome the problems identified to improve the quality and effectiveness of education.
\end{abstract}

Keywords: managerial, school inspectors, supervision

Abstrak: Pelaksanaan supervisi manajerial adalah kegiatan profesioal yang dilakukan pengawas sekolah dalam rangka membantu kepala sekolah guna meningkatkan mutu dan efektifitas penyelenggaraan pendidikan dan pembelajaran. Penelitian ini bertujuan mendeskripsikan perencanaan supervisi manajerial, pelaksanaan supervisi manajerial, dan umpan balik atau tindak lanjut supervisi manajerial pengawas di dabin 7 UPTD Pendidikan Kecamatan Purwodadi. Jenis penelitian kualitatif dan etnografi dengan subjek penelitian pengawas sekolah dan kepala sekolah . Teknik pengumpulan data dengan wawancara, observasi, dan dokumentasi. Teknik analisis data dengan analisis alur dengan proses pengumpulan data melalui reduksi data, display data dan verifikasi. Keabsahan data menggunakan triangulasi dan sumber. Hasil penelitian, 1) Perencanaan supervisi manajerial meliputi, a. Penyusunan jadwal supervisi manajejerial, b. Penyusunan Instrumen supervisi manajerial, c. Menyusun daftar sekolah yang akan disupervisi. 2) Pelaksanaan supervisi manajerial. Pada kegiatan ini supervisor menilai kinerja kepala sekolah.Ada tiga tahap dalam pelaksanaan supervisi manajerial yaitu, tahap kegiatan awal, tahap pelaksanaan atau kegiatan inti dan kegiatan penutup 3) Fungsi Umpan balik supervisi manajerial adalah memperbaiki temuan-temuan ketidak sesuaian atau mengatasi permasalahan yang ditemukan, sehingga dapat meningkatkan mutu dan efektifitas penyelenggaraan pendidikan

Kata Kunci: manajerial, pengawas sekolah, supervisi 


\section{Pendahuluan}

Supervisi adalah kegiatan professional yang dilakukan oleh pengawas Sekolah dalam rangka membantu kepala Sekolah, guru dan tenaga kependidikan lainnya guna meningkatkan mutu dan efektivitas penyelenggaraan pendidikan dan pembelajaran. Supervisi ditujukan pada dua aspek yakni: manajerial dan akademik. Supervisi manajerial menitik beratkan pada pengamatan pada aspek-aspek pengelolaan dan administrasi Sekolah yang berfungsi sebagai pendukung (supporting) terlaksananya pembelajaran.

Menurut Danim (2011:154) supervisi adalah proses kerja supervisor dalam mendiagnosis, menentukan focus, melakukan bimbingan professional, dan menilai peningkatan profesionalitas guru dalam melaksanakan proses pembelajaran, baik secara individual maupun secara kolektif. Supervisi adalah proses bimbingan professional untuk meningkatkan derajat profesionalitas guru bagi peningkatan mutu proses pendidikan dan pembelajaran,khususnya prestasi belajar siswa.

Supervisi adalah kegiatan yang dilakukan oleh pengawas satuan pendidikan dalam rangka membantu kepala sekolah, guru dan tenaga kependidikan lainnya guna meningkatkan mutu dan efektivitas penyelenggaraan pendidikan dan pembelajaran. Supervisi ditujukan pada dua aspek yaitu manajerial dan akademik.Supervisi manajerial menitik beratkan pada pengamatan pada aspekaspek pengelolaan dan administrasi sekolah yang berfungsi sebagai pendukung (supporting) terlaksananya pembelajaran. Sementara supervisi akademik menitik beratkan pada pengamatan supervisor terhadap kegiatan akademik, berupa pembelajaran baik di dalam maupun di luar kelas.

Menurut Sudjana ( 2012:54 ) kompetensi pengawas sekolah seharusnya berangkat dari duakonsep dasaryakni(1)hakikatpengawasan profesional (supervisi) dan (2) tugas pokok fungsi dan tanggung jawab pengawas sekolah yang mencakup pengawasan akademik dan pengawasan manajerial. Dalam Panduan Pelaksanaan Tugas Pengawas Sekolah/Madrasah (Direktorat Tenaga Kependidikan, 2012:20) dinyatakan bahwa supervisi manajerial adalah supervisi yang berkenaan dengan aspek pengelolaan sekolah yang terkait langsung dengan peningkatan efisiensi dan efektivitas sekolah yang mencakup perencanaan, koordinasi, pelaksanaan, penilaian, pengembangan kompetensi sumberdaya manusia (SDM) kependidikan dan sumberdaya lainnya. Dalam Supervisi yang dilakukan oleh kepala sekolah menuju pada peningkatan mutu pendidikan secara umum, dan sekolah serta pembelajaran secara khusus. Secara spesifik supervisi yang ditujukan bagi peningkatan mutu sekolah dari segi pengelolaan disebut dengan supervisi manajerial. Hal ini tentu tidak kalah penting dibandingkan dengan supervisi akademik yang sasarannya adalah guru dan pembelajaran. Tanpa pengelolaan sekolah yang baik, tentu tidak akan tercipta iklim yang memungkinkan guru bekerja dengan baik.

Supervisi manajerial menitik beratkan pada pengamatan pada aspek-aspek pengelolaan dan administrasi sekolah yang berfungsi sebagai pendukung (supporting) terlaksananya pembelajaran. Supervisi manajerial adalah supervisi yang berkenaan dengan aspek pengelolaan sekolah yang terkait langsung dengan peningkatan efisiensi dan efektivitas sekolah yang mencakup perencanaan, koordinasi, pelaksanaan, penilaian, pengembangan kompetensi sumberdaya manusia (SDM) kependidikan dan sumberdaya lainnya (Kemendiknas, 2011: 20).

Tujuan penelitian ini adalah 1) Mendiskripsikan perencanaan supervisi manajerial pengawas di dabin 7 UPTD 
Pendidikan Kecamatan Purwodadi, 2) Mendiskripsikan pelaksanaan supervisi manajerial pengawas di dabin 7 UPTD Pendidikan Kecamatan Purwodadi. 3) Mendiskripsikan umpan balik supervisi manajerial pengawas di dabin 7 UPTD Pendidikan Kecamatan Purwodadi

\section{Metode}

Penelitian kualitatif merupakan prosedur penelitian yang menghasilkan data deskriptif berupa kata-kata tertulis atau lisan dari orang-orang dan perilaku yang dapat diamati. Penelitian ini juga dikatakan penelitian kualitatif karena penelitian menggunakan latar belakang alamiah, dengan maksud menafsirkan fenomena yang terjadi dan dilakukan dengan jalan melibatkan berbagai metode yang ada (Denzin dan Guba dalam Moleong, 2012: 5)

Subyek penelitian ini adalah pengawas sekolah dan kepala sekolah di dabin 7 UPTD Pendidikan kecamatan Purwodadi.

Metode pengumpulan data merupakan langkah yang paling utama dalam penelitian, karena tujuan utama dari penelitian adalah mendapatkan data. Tanpa mengetahui metode pengumpulan data maka peneliti tidak akan mendapatkan data yang memenuhi standar data yang ditetapkan (Sugiyono, 2012: 308).

Keabsahan data menurut Moleong (2012: 320) diperlukan teknik pemeriksaan yang didasarkan atas kriteria: 1) derajat kepercayaan (credibility); 2) keteralihan (transferabilitas); 3) ketergantungan (dependability); 4) kepastian (confirmbility).

Teknik analisis data adalah data yang sudah terkumpul dalam penelitian ini kemudian dianalisis berdasarkan model analisis interaktif yang dikembangkan oleh Miles \& Huberman . Ada empat komponen analisis yang dilakukan dengan model ini, yaitu pengumpulan data, reduksi data, display data, dan penarikan kesimpulan/verifikasi. Masing-masing komponen berinteraksi dan membentuk suatu siklus. Moleong
(2012: 25) menegaskan bahwa pekerjaan analisis data adalah mengatur, mengurutkan, mengelompokkan, memberikan kode, dan mengkategorikannya. Tujuannya adalah menemukan makna yang akhirnya bisa.

Triangulasi adalah teknik pemeriksaan keabsahan data yang memanfaatkan sesuatu yang lain. Di luar data itu untuk keperluan pengecekan atau sebagai pembanding terhadap data itu. Teknik triangulasi yang paling banyak digunakan adalah pemeriksaan melalui sumber lainnya. (Moleong, 2013:330).

\section{Hasil dan Pembahasan}

\section{Persiapan pelaksanaan supervisi manajerial pengawas di Dabin 7 UPTD Pendidikan Kecamatan Purwodadi}

Supervisi manajerial menitik beratkan pada pengamatan terhadap aspek-aspek pengelolaan dan administrasi sekolah yang berfungsi sebagai pendukung (supporting) terlaksananya pembelajaran. Perencanaan supervisi manajerial dibuat pada awal tahun pelajaran yang disusun dalam program kerja pengawas dilandasi oleh hasil pengawasan pada tahun sebelumnya. Supervisi manajerial bertujuan agar Kepala sekolah lebih mampu dalam mengelola dan memimpin lembaga pendidikan untuk meningkatkan mutu penyelenggaraan pendidikan .

Program kerja pengawas memuat tentang jadwal supervisi manajerial, instrumen supervisi manajerial dan daftar sekolah yang akan disupervisi.

Dalam perencanaan langkah pertama yang dilakukan pengawas adalah menyusun jadwal pelaksanaan supervisi manajerial yang memuat tentang waktu pelaksanaan supervisi manajerial dan nama sekolah yang akan di supervisi.Setelah jadwal tersusun kemudian disosialisasikan kepada sekolah binaan.

Sarana pendukung supervisi manajerial adalah buku kunjungan dan instrumen supervisi manajerial.Instrumen supervisi manajerial disusun oleh pengawas sekolah 
berdasarkan pedoman buku kerja pengawas. Manfaat instumen untuk menilai kinerja kepala sekolah dalam mengelola dan memimpin lembaga pendidikan.Insrumen supervisi manajerial yang digunakan memuat 10 indikator tentang pengelolaan dan administrasi sekolah.

Hal ini sesuai penelitian yang dilakukan oleh Caires (2014) yang menyatakan bahwa pengalaman dan kinerja guru dan kepala sekolah dievaluasi dengan menggunakan instumen. Instrumen disusun dalam beberapa dimensi,masing-masing dimensi dinilai dengan skala tertentu sehingga dapat diketahui kwalitas dari kepala sekolah

Daftar sekolah yang akan di supervisi disusun oleh pengawas sekolah yang memuat tentang nama sekolah yang akan disupervisi dan nama kepala sekolah di dabin 7 UPTD Pendidikan Kecamatan Purwodadi.

Penelitian ini mempunyai persamaan dengan penelitian yang dilakukan oleh Obiweluozor.2013.Penelitian ini berhubungan dengan konsep pengawasan dan inspeksi, dan pengawasan serta strategi yang untuk meningkatkan pengawasan dan pemeriksaan pendidikan dasar yang efektif. Persamaan dengan penelitian ini adalah bahwa harus dilaksanakan pengawasan guna melangsungkan proses kinerja yang efektif sehingga dapat meningkatkan mutu pendidikan. Rekomendasi dibuat untuk memastikan pengawasan dan pemeriksaan yang efektif di tingkat pendidikan dasar .

\section{Pelaksanaan supervisi manajerial pengawas di Dabin 7 UPTD Pendidikan Kecamatan Purwodadi}

Pelaksanaan supervisi manajerial yang dilakukan di Dabin 7 UPTD Pendidikan Kecamatan Purwodadi dilakukan dengan berpedoman kepada proses atau langkahlangkah yang sudah ditetapkan dalam perencanaan.

Supervisi harus mampu menciptakan hubungan kemanusiaan yang harmonis.
Hubungan kemanusiaan yang harus diciptakan harus bersifat terbuka, kesetiakawanan, dan informal. Hubungan demikian bukan saja antara supervisor dengan Kepala Sekolah, melainkan juga antara supervisor dengan pihak lain yang terkait dengan program supervisi. Oleh sebab itu, dalam pelaksanaannya supervisor harus memiliki sifat-sifat seperti: sikap membantu, memahami, terbuka, jujur, ajeg, sabar, antusias, dan penuh humor.

Kegiatan awal pelaksanaan supervisi manajerial yang dilakukan pengawas di Dabin 7 UPTD Pendidikan Kecamatan Purwodadi adalah menjelaskan maksud dan tujuan kedatangan pengawas di sekolah,menjelaskan format penilaian kinerja kepala sekolah dan menyepakati skenario penilaian kinerja kepala sekolah.

Penelitian ini bertentangan dengan penelitian yang dilakukan oleh Kayani(2011). Mengungkapkan bahwa pengawas tidak mengunjungi sekolah untuk memfasilitasi dalam memecahkan masalah,mereka berperilaku otokratis ,otiriter dan tidak percaya dengan konsep pengawasan.

Pada kegiatan inti Supervisor menilai kinerja Kepala Sekolah yang dituangkan dalam instrumen penilaian kinerja Kepala Sekolah yaitu

berkenaan dengan aspek pengelolaan dan administrasi sekolah dengan langkah -langkah dan jadwal kegiatan yang telah disepakati bersama sekaligus mencatat halhal yang kurang sesuai.

Penelitian ini sejalan dengan penelitian yang dilakukan oleh Yuguda (2014). Persamaan dengan masalah pengawasan. dalam penelitian ini adalah untuk menilai peran umum pengawas sekolah dalam meningkatkan kualitas pengajaran dan efektivitas pengawasan sekolah.

Pada kegiatan penutup supervisor menjelaskan kepada kepala sekolalah tentang hasil penilaian yang telah dilaksanakan. Setelah menilai kinerja Kepala Sekolah 
supervisor memaparkan hasil kinerja kepala sekolah dengan menunjukkan segi- segi kekuatan dan kelemahannya dan memberi motivasi kepada Kepala Sekolah untuk selalu meningkatkan kinerjanya kemudian secara bersama - sama untuk menentukan agenda berikutnya sehingga kualitas mutu sekolah meningkat.

Penelitian ini sama penelitian yang dilakukan oleh Yuguda (2014).Penelitian bermaksud untuk membuat review pada beberapa masalah yang berkaitan dengan pengawasan menekankan profil profesional dan peran dalam sistem pendidikan, khususnya dalam kualitas perbaikan sekolah dan juga menyoroti konsep pengawasan dapat meningkatkan kualitas mutu serta kualitas dalam mengajar dan belajar. Oleh karena itu, disarankan agar pengawas sebagai katalis harus memfasilitasi pelaksanaan berbagai peran yang akan memperbaiki mutu pendidikan.

\section{Umpan balik supervisi manajerial pengawas di Dabin 7 UPTD Pendidikan Kecamatan Purwodadi}

Supervisi manajerial di Dabin 7 UPTD Pendidikan Kecamatan Purwodadi dari hasil yang diperoleh, pengawas sekolah melakukan tindak lanjut secara individu sesuai dengan permasalahan yang ada pada sekolah masing-masing, yang intinya berkaitan dengan pengelolaan sekolah yang berdasarkan kepada pencapaian 8 standar nasional pendidikan (SNP)

Menurut kepala sekolah pelaksanaan supervisi managerial banyak memberikan dampak positif bagi kepala sekolah.Dengan supervisi kepala sekolah dapat mengetahui segi kelebihan dan kekurangan secara dini dan dapat memberi motivasi kepala sekolah dalam mengelola dan memimpin lembaga pendidikan untuk meningkatkan mutu penyelenggaraan pendidikan.

Tindak lanjut yang dilakukan pengawas Dabin 7 UPTD Pendidikan Kecamatan
Purwodadi dalam dua buah bentuk yaitu 1) tindak lanjut korektif dengan memperbaiki temuan ketidak sesuai dalam pengelolaan sekolah dan 2) tindak lanjut preventif yang berupa upaya untuk mengatasi timbulnya permasalahan yang sama dimasa yang akan datang. Tindak lanjut supervisi manajerial merupakan tindakan yang dilakukan oleh kepala sekolah dan pengawas Dabin 7 UPTD Pendidikan Kecamatan Purwodadi dalam rangka memperbaiki temuan-temuan ketidak sesuaian atau mengatasi permasalahan yang ditemukan. Temuan dalam kegiatan supervisi dapat dikategorikan berdasarkan tingkat kepentingannya, berdasarkan dampak yang ditimbulkan, frekuensinya..Efektivitas tindak lanjut supervisi manajerial dalam mengatasi ketidak sesuaian atau temuan bergantung dari ketepatan dalam melakukan analisis akar penyebab masalah dan pemilihan alternatif solusi yang dipilih untuk mengatasi permasalahan.

Bentuk tindak lanjut supervisi manajerial yang dilakukan pengawas Dabin 7 UPTD Pendidikan Kecamatan Purwodadi adalah dengan pembinaan terpadu yaitu pembinaan yang dilakukan secara terpadu dalam lingkungan sekolah, untuk menyamakan persepsi tentang bidang tugas kepala sekolah, kebersamaan dalam upaya pengelolaaan sekolah sesuai dengan standar yang telah ditetapkan oleh pemerintah, menjaga ketahanan sekolah dan lain sebagainya.

Pengawas Sekolah membuat laporan per Sekolah dan seluruh Sekolah binaan diserahkan kepada koordinator pengawas (KORWAS) Sekolah atau ketua kelompok pengawas Sekolah (KKPS) kemudian menyampaikan laporannya kepada Kepala Dinas Pendidikan. Laporan hasil supervisi berfungsi sebagai dokumen pertanggung jawaban kegiatan pengawas..Laporan hasil supervisi dapat dijadikan sebagai indikator output kegiatansupervisi. Dalam hal lain Laporan pengawasan bertujuan untuk mengkomunikasikan secara jelas 
mengenai kekuatan dan kelemahan Sekolah, meliputi keseluruhan kualitasnya, standar pencapaian kinerja kepala Sekolah, guru dan tenaga kependidikan lainnya di Sekolah yang bermuara pada prestasi belajar peserta didik, dan apa yang harus dilakukan untuk memperbaiki hal yang dibutuhkan. Bagi pengawas laporan hasil pengawasan dapat dimanfaatkan untuk kepentingan berikut. Sebagai landasan dalam penyusunan program kerja pengawasan tahun berikutnya; mengetahui keterlaksanaan program. Sebagai dokumentasi kegiatan yang telah dilakukan dalam satu periode pengawasan (semester). Sebagai bukti pertanggungjawaban pengawas yang bersangkutan atas tugas dan fungsinya dalam penilaian, pembinaan dan pemantauan Sekolah yang dibina.

\section{Simpulan}

Perencanaan supervisi manajerial dibuat pada awal tahun pelajaran yang disusun dalam program kerja pengawas dilandasi oleh hasil pengawasan pada tahun sebelumnya. Supervisi manajerial bertujuan agar Kepala sekolah lebih mampu dalam mengelola dan memimpin lembaga pendidikan untuk meningkatkan mutu penyelenggaraan pendidikan .

Program kerja pengawas memuat tentang jadwal supervisi manajerial, instrumen supervisi manajerial dan daftar sekolah yang akan disupervisi.

Jadwal supervisi manajerial dibuat oleh pengawas sekolah yang memuat tentang waktu pelaksanaan dan nama sekolah yang akan disupervisi.Jadwal yang telah tersusun kemudian disosialisasikan kepada kepala sekolah binaan.

Sarana pendukung supervisi manajerial adalah instrumen supervisi manajerial. Instrumen supervisi manajerial disusun oleh pengawas sekolah berdasarkan buku pedoman kerja pengawas. Manfaat instumen untuk menilai kepala sekolah dalam mengelola dan memimpin lembaga pendidikan.
Daftar sekolah yang akan dibina disusun oleh pengawas berdasarkan surat keputusan dari kepala UPTD yang memuat tentang nama sekolah yang akan dibina dan nama kepala sekolah.

Kegiatan awal pelaksanaan supervisi manajerial yang dilakukan pengawas di Dabin 7 UPTD Pendidikan Kecamatan Purwodadi adalah menjelaskan maksud dan tujuan kedatangan pengawas di sekolah,menjelaskan format penilaian kinerja kepala sekolah dan menyepakati skenario penilaian kinerja kepala sekolah.

Pada kegiatan inti Supervisor menilai kinerja Kepala Sekolah yang dituangkan dalam instrumen penilaian kinerja Kepala Sekolah yaitu berkenaan dengan aspek pengelolaan dan administrasi Sekolah dengan langkah -langkah dan jadwal kegiatan yang telah disepakati bersama sekaligus mencatat hal-hal yang kurang sesuai.

Pada kegiatan penutup supervisor menjelaskan kepada kepala sekolalah tentang hasil penilaian yang telah dilaksanakan. Setelah menilai kinerja Kepala Sekolah supervisor memaparkan hasil kinerja kepala sekolah dengan menunjukan segi- segi kekuatan dan kelemahannya dan memberi motivasi kepada Kepala Sekolah untuk selalu meningkatkan kinerjanya kemudian secara bersama-sama untuk menentukan agenda berikutnya .

Supervisi manajerial di Dabin 7 UPTD Pendidikan Kecamatan Purwodadi dari hasil yang diperoleh, pengawas sekolah melakukan tindak lanjut secara individu sesuai dengan permasalahan yang ada pada sekolah masingmasing.

Tindak lanjut yang dilakukan pengawas dalam dua buah bentuk yaitu tindak lanjut korektif dengan memperbaiki temuan ketidak sesuaian dalam mengelola sekolah dan tindak lanjut preventif yang berupa upaya untuk mengatasi timbulnya permasalahan dimasa yang akan datang. Bentuk tindak lanjut supervisi manajerial yang dilakukan 
pengawas dengan pembinaan terpadu yaitu pembinaan yang dilakukan secara terpadu dalam lingkungan sekolah.

Setelah akhir kegiatan pengawas membuat laporan hasil kepengawasan dan diserahkan kepada koordinator pengawas
(KORWAS) Sekolah atau ketua kelompok pengawas Sekolah (KKPS) kemudian menyampaikan laporannya kepada Kepala Dinas Pendidikan. Laporan hasil supervisi berfungsi sebagai dokumen pertanggung jawaban kegiatan pengawas.

\section{Daftar Pustaka}

Arikunto Suharsini. 2012. Dasar-dasar Supervisi. Jakarta: Rineke Cipta

Direktorat Jenderal Peningkatan Mutu Pendidik dan Tenaga Kependidikan Depdiknas. (2011). Metode dan Teknik Supervisi. Jakarta: Depdiknas

Direktorat Tenaga Kependidikan. 2012. Panduan Pelaksanaan Tugas Pengawas Sekolah

Engkoswara. (2011). Dasar-dasar Administrasi Pendidikan.Bandung : Alfabeta.

Herabudin. 2012. Administrasi dan Supervisi pendidikan. Bandung : Pustaka Setia

Isa Yuguda Kotirde.2014.The supervisor's role for improving the quality of teaching and learning in Nigeria secondary school educational system. International Journal of Education and Research Vol. 2 No. 8 August 2014.

Miles, Mattew B dan Amichael Huberman. 2011. Analisis Data Kualitatif Buku Sumber tentang Metode-Metode Baru. Terjemahan Tjetjep Rohendi Rohisi. Jakarta: Universitas Indonesia.

Moleong, L.J. 2012. Metodologi Penelitian Kualitatif, Bandung: Remaja Rasda Karya

Muhammad Munir Kayani. 2011. Concept of Supervision and Supervisory Practices at Primary Level in Pakistan. International Education Studies Vol. 4, No. 4; November 2011

Nkechi Obiweluozor.2013.Supervision and inspection for effective primary Education in nigeria: strategies for improvement. Academic Research International. ISSN-L: 22239553, ISSN: 2223-9944 Vol. 4 No. 4 July 2013.

Norhasni Zainal Abiddin. 2011. Effective Supervisory Approach in Enhancing Postgraduate Research Studies. International Journal of Humanities and Social Science Vol. 1No. 2; February 2011.

Pidarta, M. 2012. Supervisi Pendidikan Kontekstual. Bandung : Rineka Cipta

Purwanto,Ngalim. 2011.Administrasi dan Supervisi Pendidikan. Bandung: PT. Remaja Rosdakarya

Semiha Şahin. 2011. Education Supervisors' Views Regarding Efficiency of Supervision System and In-service Training Courses. Educational Sciences: Theory \& Practice 11(3) • Summer • 1196-1201.

Sudjana, Nana,dkk. 2013. Menyusun Program Pengawasan.Jakarta. Binamitra-Publishing 
Sudjana, Nana. 2012. Pengawas dan Kepengawasan. Cikarang. Binamitra-Publishing

Sugiyono. 2006. Metode Penelitian Pendidikan Pendekatan Kuantitatif, Kualitatif, dan R \& $D$. Bandung: Alfabeta.

Sukmadinata. 2011. Metode Penelitian Pendidikan. Bandung: PT. Remaja Rosda Karya. 